\title{
Profitability Prediction Model for NPD Projects Under Risk*
}

\author{
Tae Yeon Hwang \\ VMS Solutions, Daejeon, Republic of Korea \\ Hoo-Gon Choi \\ Sungkyunkwan University, Suwon, Republic of Korea
}

\begin{abstract}
Only a few successful new product development (NPD) projects are continuously supported by the firm when they are expected to assure profitability in the market. The profitability of a project is measured as profit ratio (PR), the profit is divided by the cost. The profit figure is changed depending on either internal risks or uncertainties occurring externally. More risks require higher response costs to them and uncontrollable uncertainties affect NPD projects either positively or negatively. In this study, a PR model is developed to predict the profitability of a project at a given time. The model minimizes the response cost computed under two extreme response strategies, such as "Avoid" and "Acceptance" for the internal threats. Also, the model reflects the sales volume changes due to external uncertainties. The linear programming (LP) method determines the optimal probability of the response strategy under three scenarios of defining the relationship between risk avoidance and risk acceptance. It can be utilized to make a GO/NOGO decision on the project based on the prediction results at any gate of the NPD process.
\end{abstract} The solving procedure is provided to apply the developed model for real cases.

Keywords: NPD, risk assessment, response costs, profit ratio model, profitability prediction, GO/NOGO decision making

\section{Introduction}

A firm can attain competitive advantage and survival from tough competition in a rapidly changing market environment through successful NPD efforts that promise high return or profit. It is reported that $42 \%$ of sales volume and $38 \%$ of profits have been generated by successful NPD efforts in the top $20 \%$ of 105 US corporations (Cooper, 2004). A new product can substitute for an existing product on the decline, in terms of sales volume, profit, and technology. However, all NPD projects are not successful due to a lower profit rate than expected. Nevertheless, a large amount of resources and efforts are put into them under serious uncertainty. Numerous projects have failed due to unsolvable or unexpected risks and inefficient project management, or insensible changes of both the internal and external environment of firms (Cooper, 1999). Other important reasons for project failures include lack of budget, government regulation change, market segmentation, economic shift, rapid technology change, capricious customer needs, and short product life cycle. Therefore, a

\footnotetext{
* Project Supported: This work was supported by National Research Foundation of Korea (NRF) grants funded by the Korea government (MEST) (NRF-2011-0016602 and NRF-2012R1A1A2045906).

Tae Yeon Hwang, assistant manager/Ms., VMS Solutions, Daejeon, Republic of Korea.

Hoo-Gon Choi, professor/Ph.D., Department of Systems Management Engineering, Sungkyunkwan University, Suwon, Republic of Korea.

Correspondence concerning this article should be addressed to Hoo-Gon Choi, Department of Systems Management Engineering, Sungkyunkwan University, Suwon 16419, Republic of Korea.
} 
firm should develop a more scientific and logical decision making process to select the right projects at the right time to decide GO/NOGO of a project at the gates of the NPD process, and to allocate superior resources to it. Rubenstein, Chakrabarti, O'Keefe, Souder, and Young (1976) presented that a firm with an outstanding decision making process has a higher success rate for NPD based on analyzing 54 NPD projects.

A firm should manage NPD projects effectively and efficiently to ensure their success through the right decision making process with precise decision criteria. A critical criterion is the earnings or profit figure generated from successful market launch of a NPD project. If a project manager can estimate the amount of profit to be expected at any time of the NPD procedure, he/she can decide the life of the project, i.e. GO/NOGO decision on the project. The profit is determined by sales volume in money value minus project costs. A firm would invest more resources, including superior experts, in terms of technology, finance, and management to the projects expecting high profit.

The NPD process typically consists of six phases or stages, such as planning or requirement analysis, conceptual design, system-level design, detailed design, test and simulation, and production ramp-up. Each phase has many subsequent functions or activities. Examples of the functions are customer's requirements analysis, design guidelines development, evaluation of design to cost, producibility measurement, manufacturing procedure determination, etc. More importantly, there are gates between phases to evaluate the project performance at the end of a phase. The project manager should decide which project is to be continued or terminated at each gate based on its performance. The performance figure is changing due to various risks occurring in phases. Examples of the risks are market change, product complexity, resource tightness, technical risk, government regulation, and interest rate. A firm should respond to the risks appropriately to minimize the impact on the project. Various strategies to respond against risks are available, depending on risk types, such as internal and external (Li, Akintoye, Edwards, \& Hardcastle, 2004) and risk impact, such as threat and opportunity (Hillson, 2001). Risk acceptance, risk avoidance, risk reduction, and risk transfer are appropriate for dealing with threats, while "exploit", "share", "enhance", and "ignore" are new strategies proposed to respond to identified opportunities. However, effective or efficient responses lead to increasing project costs, especially for threats, no matter which strategy is adopted (Barton \& Bobst, 1988; Murmann, 1994; Walid \& Oya, 1996).

The project manager should control NPD projects through not only experience, but also a scientific and logical risk management plan. If the plan is optimized quantitatively, the manager can control the NPD projects consistently. This study suggests a quantitative profit ratio (PR) prediction model by which the GO/NOGO decision on a project can be made at each gate. The model can predict the profit to be expected at the production ramp-up stage where both internal and external risks may impact as threats. If a project proceeds to the production ramp-up stage successfully, i.e. passing all previous gates of the NPD process, the new products presumed by the project are produced and sold in targeted markets. All expenses paid for the project survival should be recovered by sales volume in money. The major costs include fixed and variable cost, and response costs invested in treating all types of risks, especially for threats. In this study, the risks are treated by two response strategies, risk avoidance and risk acceptance. The developed PR model consists of these costs that are minimized by the optimized response strategies, and considers sales volume changes impacted by external risks. A project predicted to generate a high profit ratio at a certain gate should pass the corresponding gate and be continuously supported by the firm till its next gate.

After the introduction, the remainder of the paper is structured as follows: Relevant previous research related to risks in NPD, risk degree measurement, and types of responses against risks are presented in section 2. 
The profitability prediction framework and the application steps of the framework for real cases are described in section 3. In section 4, conclusion and discussion including the limitations of the model are remarked.

\section{Related Work}

Many risks either positively or negatively affect the success of NPD projects in terms of customer's satisfaction, financial measures, firm's reputation, and product excellence. The risks can be either threats or opportunities, depending on occurrence time and project progress. For example, a risk, such as money exchange rate fluctuation during the NPD process, will be carefully evaluated to decide its impact on a project, as being sensitive or not. However, all types of risk need expenses for a firm's response. These affect the expected profit to be earned from the project.

Risks can be classified into two groups: internal and external. The internal group contains the risks related to difficulties from features of the project itself and project management. The typical feature of the group is the project complexity caused by task, forecasting, communication, and teamwork that influences project speed and performance (Kim \& Wilemon, 2003). The difficulties of project management come from technical risks in the areas of design, test, production, facilities, and management, as other examples of internal risk. Technical risk is a measure of the level of uncertainty for all technical aspects of the NPD process (Polk, Plank, \& Reid, 1996; Priest \& Sanchez, 2001). Product innovativeness, design uniqueness, and project structure are also affected by internal risks (Ernst, 2002; Song \& Montoya-Weiss, 1998). The external risk group can be characterized by three features: dynamism, hostility, and heterogeneity (Park, Kim, Lee, \& Choi, 2011). Dynamism means that risks are not anticipatable and unstable due to their frequent occurrence, like customer's need changes and competitors's strategy. The risks related to hostility occur due to competitors' growth speed or decline in economic activity. The heterogeneity of risks is characterized by unfamiliar circumstances, such as new production technology, markets, and customers. The smooth flow of the NPD process and its management are hindered by the unpredictable external risks. Then, NPD projects and related activities require more resources than expected and need a better management system.

The risk degree is a measure by which the amount of impact is estimated for a risk to either positively or negatively affect the success of NPD projects. The success of a NPD project can be measured by different aspects, such as customer, finance, firm itself, and product (Griffin \& Page, 1993). Also, other aspects in management can be involved (C. S. Kim, J. S. Kim, Lee, \& Choi, 2013). The financial aspect is the most critical if a firm wants to profit from the successful launch of new products to market. For this reason, development of quantitative models to measure the risk degree and to predict expected profit from a project is important to evaluate the project future or project life. In general, both more time and higher cost should be invested to a project to be successful, when more risks occur more frequently. If suitable responses are not available against risks, the project can be delayed or fail. Therefore, it is necessary for a project manager to measure the risk degree and profit scientifically and quantitatively.

The DEA (Data Envelopment Analysis) and AHP (Analytical Hierarchy Processing) have been known as methods to evaluate the risk (Wang, Liu, \& Taha, 2008; Bae \& Lee, 2011). Especially, Bae and Lee (2011) suggested the IDEA (Imprecise Data Envelopment Analysis) method to develop risk management process, which transforms the imprecise data so that it can be used to represent risk. Choi and Ahn (2010) introduced a framework in which the risk degree can be measured through a fuzzy process and stochastic process, and integrated risk degree was determined for all risks occurring in a NPD project. Song, Ming, and Xu (2013) 
proposed quantitative methods to evaluate risk factors in customer's integration for NPD. They used rough set theory and group AHP approach to develop a risk evaluation framework without requiring prior information by which subjectivity and vagueness of judgement under uncertain environment. However, their methods focus on only risks related to customer's integration without considerations of all possible risks occurred in NPD stages. Park et al. (2011) compared the risk degrees measured by fuzzy process and Grey system theory (Deng, 1985). H. G. Choi and D. Choi (2012) classified the risks into phases or stages of the NPD process, measured the risk degrees by each phase and integrated them for the entire NPD process, and selected optimal responses to risks using linear programming models. Their studies did not consider either threats or opportunities for each risk to be dependent on occurrence time and current status of a project. Especially, they did not consider success measures to evaluate the project. In general, the success of a project is decided by expected profit to be earned from a given market. If the profit size can be estimated or predicted at each phase or stage of the NPD process for a project, the project manager can reallocate critical resources to it, and furthermore, he/she can make a decision for it to be continued or stopped. Since a risk affects a project in terms of both response cost to be paid for mitigating its impact and project schedule, the profit could be reduced.

The risk degree should be reduced by the most appropriate responses against an identified risk. The manager is responsible for implementing the responses and for monitoring them effectively. Risk responses are usually grouped into four strategies according to their intended effect on the risk being treated (Hillson, 1999): "Avoid", "Transfer", "Mitigate", and "Accept". These strategies are appropriate for dealing with threats. "Avoid" is the strategy to make risk occurrence probability zero or to make the risk impact zero. This strategy can recommend different ways to project manager to perform the project. "Transfer" strategy identifies another stakeholder better able to manage the risk, to which the liability and responsibility for action can be passed. The strategy "Mitigate" reduces the impact of the risk to make it more acceptable to the project or organization. Finally, "Accept" strategy recognizes residual risks and responses either actively by allocating appropriate contingency, or passively doing nothing except monitoring the status of the risk. However, new strategies should be also developed to deal with opportunities, because no project manager would wish to "Avoid" an opportunity, or "Mitigate" its probability and/or impact. They are "Exploit", "Share", "Enhance", and "Ignore". These can be derived from the threat strategies by generalizing the approach taken for threats to make it suitable for opportunities. It is noted that the effective and efficient responses against threats lead to increasing the project costs and affect the profit. This study focuses only on the risks threatening the success of a project.

Although plentiful researches are available to measure the profit in finance fields, such as the stock market and money exchange, few studies handle the profit models to evaluate NPD projects. Also, there are few researches to predict possible profits for a given NPD project performing at its current stage on the basis of quantitative risk management model. This study develops the profit model to predict the expected earnings from a project at any gate of the NPD process and helps project managers to make decision on the project life at a given stage.

\section{PR Prediction Framework}

Cooper (2008) presented the stage-gate model for the NPD process. He showed six stages: idea, scoping, business case, development, testing, and launch. Similarly, Priest and Sanchez (2001) presented five stages: requirements definition, conceptual design, detailed design, test and evaluation, and production and sustaining engineering. Each stage has specific functions or activities to be adapted for design, test, and production. There 
are gates located between two stages to evaluate and maker GO/NOGO decision for a project, as shown in Figure 1. A project has been successful at a given stage in terms of quality, cost, product function, technical risks, etc. if it is expected to make a high profit after entrance to the market. The project must be continuously supported to perform related functions in the next stage.

\section{Hypotheses}

The profit ratio is defined by profit to cost; profit is determined by income minus cost. In this study, total expenses paid till the current gate are the sum of the cost for team operations, prototype testing and simulation, new technology adaptation, equipment, labor, material, overhead, responding against various risks, etc. The ratio is predicted at the current gate with an assumption that a project would enter successfully into the production ramp-up stage (Stage 5). If the predicted ratio is greater than 1, the corresponding project can be a GO candidate that proceeds to the next development stage.

Some critical assumptions established to develop the profit ratio model are as follows:

- The project manager can provide all necessary cost information on the basis of historical data and experience obtained from the previous NPD projects. The cost information is classified into three groups: fixed cost, variable cost, and response cost in this study. These cost groups can be classified further into either critical or non-critical costs by specifying the priorities given for managing, operating, and controlling them. This study requires all cost information regardless of the priorities to estimate the project cost (TRC).

- Internal risks affect total expenses, while external risks influence sales volume in Stage 5.

- All risks occurring in a stage must be handled and resolved by appropriate responses before entering the next stage. That is, four strategies can be considered only for threats: "Avoid", "Transfer", "Mitigate", and "Accept". It is noted that the strategy "Avoid" is the antipodes of the strategy "Accept" in terms of response cost. "Avoid" takes relatively the largest cost while "Accept" requires the least cost. Also, the former expects no project delays and the latter does not. The costs for other strategies, "Transfer" and "Mitigate", can be prorated on the basis of the costs for "Avoid" and "Accept". Furthermore, the internal risks are responded by these two strategies while the external risks are treated by "Accept" and monitoring the risk impact changes, especially the sales volume changes in the production stage.

- Using historical data, the project manager can induce probability density functions of risk occurrences for a risk.

- Market price is estimated using total cost invested in a project and profit margin.

- Time value of money is ignored: interest rate and inflation rate are not considered.

\section{Risk Assessment Model}

Either internal or external risks affect project success with unequal penalties. Therefore, effective or efficient responses against risks are necessary to reduce the impact of risks. However, the responses require the investment of resources, such as cost, time, technology, and people, especially for threats. All kinds of resources can be converted into monetary value that is utilized for developing the PR model in this study. Only the cost and time are considered in this study to calculate the profit to be expected from a given project at a development stage.

Nomenclature. The following notation and functions are used to develop the PR model:

$x=$ time point of the last gate $(i=5)$ located just before Stage 5 (Production), as shown in Figure 1 . The design maturity of a project is finally decided at this point. 
$t=$ a certain time point of the NPD process $(0 \leq t \leq x)$.

$t_{s}=\mathrm{a}$ time point at which a new product as the outcome of a NPD project is on sale. That is, a certain time point of Stage 5 in which production ramp-up is performed $\left[0 \leq t_{s} \leq \min\right.$ (one year, EOL)]. EOL is the end of product life.

$i=i^{\text {th }}$ gate $(i=2,3,4,5)$.

$z=z^{\text {th }}$ stage $(\mathrm{z}=1,2,3,4)$.

$D_{z}=$ the initially scheduled time length of $z^{\text {th }}$ stage.

$r_{z j}=j^{\text {th }}$ internal risk in $z^{\text {th }}$ stage.

$\lambda_{z j}=j^{\text {th }}$ risk occurrence rate in $z^{\text {th }}$ stage.

$\phi_{z j}=$ probability of avoiding $j^{\text {th }}$ risk occurring in $z^{\text {th }}$ stage. $\left(1-\phi_{z j}\right)$ is the probability of accepting the risk.

$X_{z j}(t)=$ response cost paid for $j^{\text {th }}$ risk at time $t$ within $z^{\text {th }}$ stage through risk avoidance.

$Y_{z j}(t)=$ length of time delay due to risk acceptance for $j^{\text {th }}$ risk at time $t$ within $z^{\text {th }}$ stage.

$d_{z}=$ actual time length of $z^{\text {th }}$ stage $=D_{z}+\sum_{\forall j}\left(1-\phi_{z j}\right) Y_{z j}(t)$.

$U C_{z}(t)=$ unit delay cost paid due to risk acceptance at time $t$ in $z^{\text {th }}$ stage.

$E R C_{i}(x)=$ expected response cost to be paid for internal risks to occur till period $x$ that is evaluated at $i^{\text {th }}$ gate.

$I C_{i}(x)=$ expected fixed cost to be paid during period $x$ that is evaluated at $i^{\text {th }}$ gate. This cost is added to the initial budget $I C_{0}(x)$ allocated to a project at Stage 0 .

$R R C_{i}(x)=$ total estimated cost that is a sum of the fixed cost to be paid at gate $i$ for time $x$ and the expected variable cost with sales volume predicted at gate $i$ for $t_{s}$.

$T R C_{i}(x)=$ total response cost at gate $i$ for $x=R R C_{i}(x)+E R C_{i}(x)$.

$P R_{i}\left(t_{s}\right)=$ expected profit ratio for time $t_{s}$ that is evaluated at $i^{\text {th }}$ gate.

$O C_{i}\left(t_{s}\right)=$ expected unit variable cost to be paid for time $t_{s}$ that is evaluated at $i^{\text {th }}$ gate.

$S_{i}\left(t_{s}\right)=$ expected sales volume for time $t_{s}$ that is evaluated at $i^{t h}$ gate.

$P_{i}\left(t_{s}\right)=$ expected price per unit for time $t_{s}$ that is evaluated at $i^{t h}$ gate.

$E S_{i}\left(t_{s}\right)=$ sales volume change due to impact from external risks for time $t_{s}$ that is evaluated at $i^{\text {th }}$ gate.

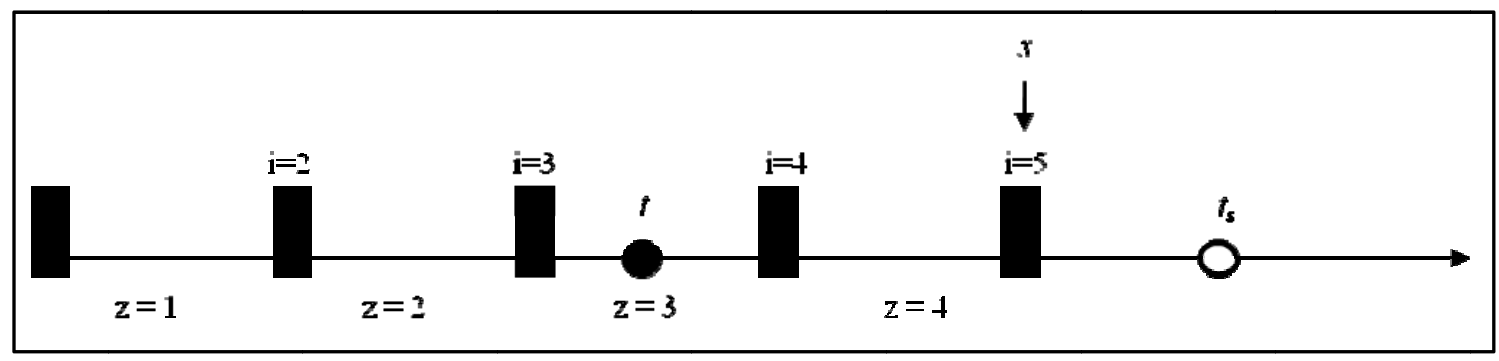

Figure 1. $x, t, t_{s}, I$, and $z$ in NPD process.

Risk assessment for internal risks. In this study, two different response strategies are used to treat the internal risks occurring at a stage: risk avoidance ("Avoid" strategy) and risk acceptance ("Accept" strategy). Risk avoidance is the complete removal of the possible occurrence of a risk. This can be done by a project budget increase or excluding any uncertain activities, parameters, functions, and cases from the NPD process. 
Conversely, risk acceptance involves that a minor or small impact from the risk is expected, changing either design or production processes is more efficient, delaying of a stage is more economical, or passively doing nothing, except monitoring the status of the risk is more desirable than risk avoidance. Risk avoidance is the antipode of risk acceptance, in terms of cost and time. This means the other two strategies, "Transfer" and "Mitigate", for threats can be also selected with some prorated cost and time, as shown in Figure 2.

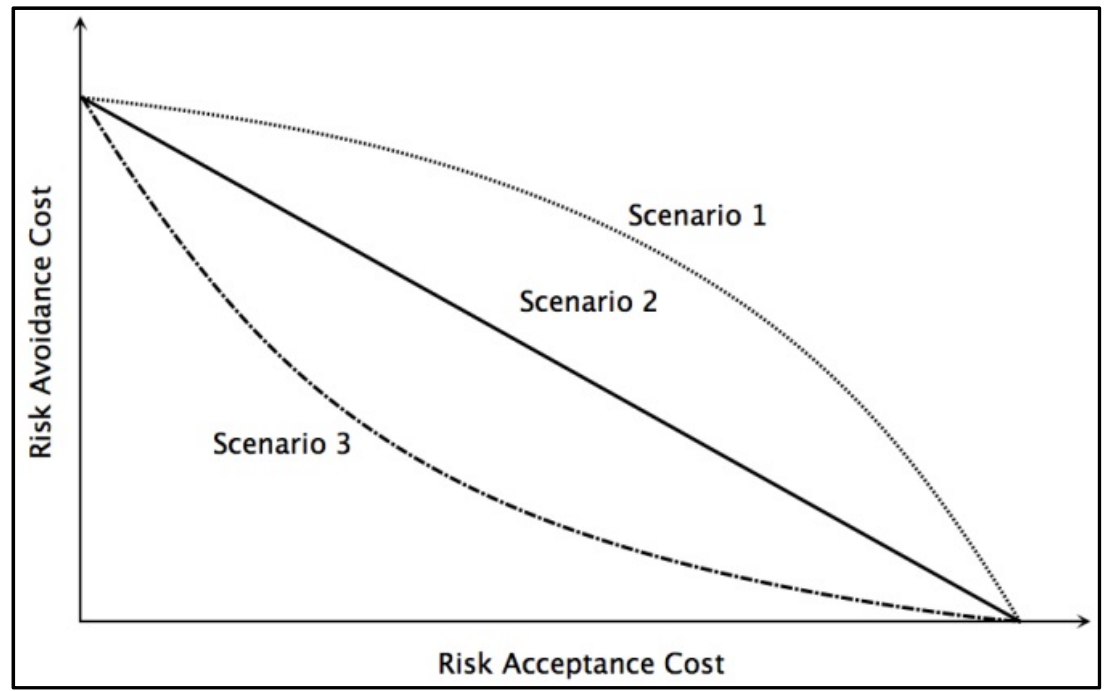

Figure 2. Three different relationships (scenarios) between risk avoidance and risk acceptance.

An exponential distribution is assumed for internal risk occurrences in this study. Then, the expected number of occurrences of $j^{\text {th }}$ risk is determined by $\lambda_{z j} \cdot d_{z}$. The expected response cost to be paid for all future internal risks after $i^{\text {th }}$ gate is determined by equation (1). The response cost is to be modified at $(i+1)^{\text {th }}$ gate in $(z+1)^{\text {th }}$ stage with new internal risks. $E R C_{i}(x)$ involves both response cost for risk avoidance and delay cost for risk acceptance. In equation (1), the decision making variable is the probability of avoiding $j^{\text {th }}$ risk occurring at $z^{\text {th }}$ stage, $\phi_{z j}$ to minimize $E R C_{i}(x)$. The optimal $\phi_{z j}$ value is obtained by the LP method. When internal risks occur, the firm must decide which strategy is better between risk avoidance and risk acceptance to minimize the response cost. Therefore, the project manager should be capable of deciding GO/NOGO for the NPD projects at gate $i$ on the basis of cost and profit. It should be noted that the profit is a predicted value for time $t_{s}$ at gate $i$. Another important consideration to compute $E R C_{i}(x)$ is the market launch time expected by the project at gate $i$. The expected launch time can be early or tardy depending on either the response cost with risk avoidance, $Y_{z j}(t)$ or the time delay with risk acceptance, $Y_{z j}(t)$. If either $X_{z j}(t)$ or $Y_{z j}(t)$ is high, the market launch time expected at gate $i$ would be delayed. The time, $Y_{z j}(t)$ can be converted to cost.

$$
E R C_{i}(x)=\sum_{z \geq i} \sum_{\forall j}\left\{\lambda_{z j} \cdot d_{z}\left[\phi_{z j} X_{z j}(t)+U C_{Z}(x)\left(1-\phi_{z j}\right) Y_{z j}(t)\right]\right\}
$$

Three scenarios define the relationship between risk avoidance and risk acceptance, as shown in Figure 2. In this study, risk avoidance is to make the risk occurrence probability zero or to make the risk impact zero through active response plans, while risk acceptance either allocates actively appropriate contingency or does passively nothing, except monitoring the status of the risk. That is, the highest response cost is expected if the most active response plans are applied to avoid a risk, while the longest delay is expected when the most passive plans are adapted for accepting the same risk. Three curves with different tangents are shown in Figure 
2. It should be noted that the cost required for treating a risk with either "Transfer" or "Mitigate" strategy can be represented as any intermediate point of these curves. Depending on one of these scenarios, $E R C_{i}(x)$ is determined after the market launch time is set. Figure 2 presents three scenarios that lead to construction of the following constraints:

For Scenario 1,

$$
\begin{gathered}
\phi_{z j}\left[X_{z j}(t)\right]^{2}+\left(1-\phi_{z j}\right)\left[U C_{Z}(x) Y_{z j}(t)\right]^{2} \leq t c_{z j} \text { for } \forall z, \forall j \\
\sum_{z \geq i-1}\left(1-\phi_{z j}\right) Y_{z j}(t) \leq c
\end{gathered}
$$

For Scenario 2,

$$
\begin{gathered}
\phi_{z j} X_{z j}(t)+\left(1-\phi_{z j}\right) U C_{Z}(x) Y_{z j}(t) \leq t c_{z j} \text { for } \forall z, \forall j \\
\sum_{z \geq i-1}\left(1-\phi_{z j}\right) Y_{z j}(t) \leq c
\end{gathered}
$$

For Scenario 3,

$$
\begin{gathered}
\phi_{z j} X_{z j}(t)-\left(1-\phi_{z j}\right) / U C_{Z}(x) \cdot Y_{z j}(t) \leq t c_{z j} \text { for } \forall z, \forall j \\
\sum_{z \geq i-1}\left(1-\phi_{z j}\right) Y_{z j}(t) \leq c
\end{gathered}
$$

where $t c_{z j}$ of each constraint is a given constant specifying the maximum budget a firm would invest to respond on $j^{\text {th }}$ internal risk occurring in $z^{\text {th }}$ stage and $c$ is the maximum allowable time delay.

As mentioned before, $E R C_{i}(x)$ is modified at every gate. Therefore, total response cost at gate $i\left(T R C_{i}(x)\right)$ can be determined by equation (5), where $R R C_{i}(x)$ is total estimated cost expected at gate $i$ for time $x . R R C_{i}(x)$ is a sum of the fixed cost, including project costs, to be paid at gate $i$ for time $x, I C_{i}(x)$ and the expected variable cost with sales volume predicted at gate $i$ for $t_{s}$.

$$
T R C_{i}(x)=R R C_{i}(x)+E R C_{i}(x)
$$

where

$$
R R C_{i}(x)=I C_{i}(x)+O C_{i}\left(t_{s}\right) \int_{0}^{t_{s}} S_{i}(x) d x
$$

The sales volume predicted at gate $i, S_{i}\left(t_{S}\right)$ can be defined as a continuous/discrete function or constant by the project manager, and changed by the external risks.

Risk assessment for external risks. Project success is influenced by not only the internal risks, but also the external risks. The external risks are often uncontrollable. Typical examples include economic shift change, oil price, stock price, and money exchange rate. These risks can impact a project positively or negatively to certain degrees at a stage. It is difficult to measure the impact accurately. However, this can be estimated quantitatively from historical data and expert knowledge. Park et al. (2011) presented a fuzzy approach and Grey system theory method to measure the impact of various external risks and Kim et al. (2013) used multiple response optimization models to evaluate their significance. This study uses a fuzzy approach to measure the impact on sales volume and profit. Triangular membership functions are assumed due to their closeness to normal distribution. Then, the positive and negative impacts of risks are evaluated on the basis of sales volume increment or decrement at time $t$, respectively. Normalization is followed to adjust the impact values between 0 
and 1 , and followed by a defuzzification process to obtain real values along with the clipped center of gravity method. Finally, sales volume change $E S_{i}\left(t_{s}\right)$ is determined by equation (6).

$$
E S_{i}\left(t_{s}\right)=1+\sum_{k} f_{i k}^{p}-\sum_{k} f_{i k}^{n}
$$

where $f_{i k}^{p}=$ positive impact of $k^{\text {th }}$ external risk at $i^{\text {th }}$ gate for time $t_{s} ; f_{i k}^{\text {n }}=$ negative impact of $k^{\text {th }}$ external risk at $i^{\text {th }}$ gate for time $t_{s \text {. }}$

\section{Profit Ratio Model}

In general, profit is determined by sales volume, unit price, and cost. When a project successfully enters Stage 5 (production stage), a firm sells developed products and obtains profit. In this study, the profit is defined by equation (7). The first term is total income from the initial point of sales $(x=0)$ to a certain time $t_{s}$ where $0 \leq$ $t_{s} \leq \min$ (one year, EOL) minus total costs paid till gate $i$ for $x$. In this study, a continuous sales function is assumed. The total sales takings are determined by total sales volume and unit price is predicted at gate $i$ for $t_{s}$. However, both the total sales takings and total estimated costs are affected by the sales volume change, $E S_{i}\left(t_{s}\right)$ made by external risks. The second term is the total response cost for the internal risks to occur for $x$. Furthermore, $P_{i}\left(t_{s}\right)$ in equation (8) is the unit price estimated at gate $i$ that is based on its initial value defined in Stage 0 and modified by both sales volume and costs in the stages to follow.

$$
\begin{gathered}
\operatorname{Profit}_{i}\left(x, t_{s}\right)=\left[\int_{0}^{t_{s}} S_{i}(x) \cdot P_{i}(x) d x-R R C_{i}(x)\right] E S_{i}\left(t_{s}\right)-E R C_{i}(x) \\
P_{i}\left(t_{s}\right)=P_{0}\left(t_{s}\right)+\left[R R C_{i}(x) \cdot E S_{i}\left(t_{s}\right)+E R C_{i}(x)\right] / S_{i}\left(t_{s}\right)
\end{gathered}
$$

$\operatorname{Profit}_{i}\left(x, t_{s}\right)$ is an estimated value at $i^{\text {th }}$ gate for time $t_{s}$ that is estimated at every gate. Then, the $P R_{i}\left(x, t_{s}\right)$ is a value of $\operatorname{Profit}_{i}\left(x, t_{s}\right)$ divided by the entire costs including fixed and variable costs, as shown in equation (9). The value should be greater than 1 . If a high profit ratio is expected, it could be used to make a decision of $\mathrm{GO} / \mathrm{NOGO}$ for a project at gate $i$.

$$
P R_{i}\left(x, t_{s}\right)=\operatorname{Profit}_{i}\left(x, t_{s}\right) /\left[R R C_{i}(x) \cdot E S_{i}\left(t_{s}\right)+E R C_{i}(x)\right]
$$

\section{Decision Making for NPD Projects}

GO/NOGO decision making at $i^{t h}$ gate for a project is done by $E R C_{i}(x)$ and $P R_{i}\left(x, t_{s}\right)$. The major decision making variable is the probability of avoiding $j^{\text {th }}$ risk occurring in $z^{\text {th }}$ stage, $\phi_{z j}$ to minimize $E R C_{i}(x) .\left(1-\phi_{z j}\right)$ is the probability of risk acceptance. In this study, the obtained value $\phi_{z j}$ is classified into three groups, as shown in Table 1. It should be noted that project manager can use various ways of grouping the probability of risk acceptance based on historical outcomes of the previous projects, or his/her own experience.

The minimum $E R C_{i}(x)$ value is plugged into $P R_{i}\left(x, t_{s}\right)$. Then, the result is compared to the threshold $P R_{i}(x$, $t_{s}$ ) value determined by the manager. If it is higher than the threshold value, the corresponding project would be continued to its next stage. The profit ratio model developed in this study can trace the changes of target sales volume and price with response costs invested for handling risks as NPD stages are proceeding.

Table 1

Classification of the Probability of Accepting Risk

\begin{tabular}{|l|l|}
\hline$\phi_{z j}$ & Description \\
\hline $0-0.4$ & Risk acceptance is more effective \\
\hline $0.4-0.6$ & "Transfer" or "Mitigate" \\
\hline $0.6-1$ & Risk avoidance is more effective \\
\hline
\end{tabular}




\section{The Solving Procedure}

Seven steps are required to apply the profit ratio model for a given example, as follows:

Step 1: Setting $S_{0}\left(t_{s}\right), P_{0}\left(t_{s}\right), I C_{0}(x)$, and $O C_{0}\left(t_{s}\right)$ at Stage 0 for time $t_{s}$.

Step 2: Setting $I C_{i}(x), D_{z}$, and $U C_{z}(t)$.

Step 3: Estimating $\lambda_{z j}, X_{z j}(t)$, and $Y_{z j}(t)$.

Step 4: Estimating the maximum budget $t c_{z j}$ to be invested for responding to $j^{\text {th }}$ internal risk in $z^{\text {th }}$ stage by using risk avoidance and the maximum allowable time delay $c$ if necessary for taking risk acceptance. Then, finding the optimal $\phi_{z j}$ to minimize $E R C_{i}(x)$ for $j^{\text {th }}$ internal risk in $z^{\text {th }}$ stage depending on three scenarios.

Step 5: Deciding for an external risk, whether its impact is either positive or negative. Then, determining sales volume change, $E S_{i}\left(t_{s}\right)$.

Step 6: Synchronizing all values obtained from the previous steps to compute the profit ratio, $P R_{i}\left(x, t_{s}\right)$ under each scenario.

Step 7: GO/NOGO decision can be made on the basis of $P R_{i}\left(x, t_{s}\right)$ at gate $i$.

The importance of historical data is emphasized again to obtain the most reasonable values for Steps 1 through 5. Suppose that multiple NPD projects have been launched at a fiscal year and each project has spent the budget allocated by the firm. Both internal and external risks are expected to be occurred after the current gate. Also, suppose that project manager can estimate mean occurrence rate of each internal risk from the firm database. Project manager should decide the optimized response strategy, either risk avoidance or risk acceptance, to respond each internal risk with minimum cost to be paid till next gate arrival. That is, the optimal $\phi_{z j}$ to minimize $E R C_{i}(x)$ for $j^{\text {th }}$ internal risk in $z^{\text {th }}$ stage, depending on three scenarios, is obtained by using the data required in Steps 1 through 5. This can be done easily through the constOptim function of Optimix library in $R^{\circledR}$ package. When the project arrives at the gate, the external risks to be occurred at sales time $t_{s}$ are predicted to measure sales volume change affecting the profit figure either positively or negatively. The sales volume change is estimated by fuzzy theory. Finally, the project manager synchronizes all cost data and risk impacts into the profit ratio model and makes GO/NOGO decision on the project depending on the profit ratio.

\section{Conclusion and Discussion}

The correct decision making on GO/NOGO for a project is difficult at a gate in the NPD process, because project success is dependent on various views, such as market, management, finance, and the firm itself (Park et al., 2011). Nevertheless, a project manager should logically allocate the most valuable resources to the most promising projects. L. M. Dragan, D. M. Dragan, and Mirjana (2010) presented the method of ranking projects, which is based on net present value (NPV), project risk, level of investment, payback period for returning the investment, and the rise of market share along with corresponding weights under different types of projects. However, their model does not give an optimal solution. Since successful new products make high profits in general, it is desirable that the project manager can predict the profit expected from a project during the NPD process with quantitative models. The profit is determined by sales volume with unit price and costs incurred in the NPD process. In this study, it is assumed that the risks occurring in a stage affect the sales volume, price, and costs. Two types of risks are considered to estimate the profit: internal risks and external risks. The internal risks are the risks related to project characteristics and require appropriate responses to mitigate their impacts on the project. The two ways to handle the internal risks are risk avoidance and risk acceptance. Since both ways incur a certain cost, depending on three different scenarios, the optimal solution is required to minimize 
the costs. The external risks are uncontrollable and assumed to either positively or negatively affect sales volume.

Although the developed framework can estimate the profit expected at the current gate, it has several limitations, as follows:

The risk occurrence rate may follow a probabilistic distribution that must be determined to utilize the framework in industries. A firm should construct databases to accumulate data related to risk types, frequencies, and occurrence times by projects.

The external risks do not occur until the production stage (Stage 5), because they are assumed to affect project survival, not successfully. That is, a project can be reluctantly killed due to external risks like terrorism or incredible change of market needs, even though its current status is successful. However, the impact of the external risks occurring before the production stage can be quantified and adapted for the developed model by handling them by either risk avoidance or risk acceptance.

All internal risks incurred till the end of Stage 4 defined as time $x$ are considered to estimate the profit expected at the current gate. However, the length of a given stage can be set as time $x$ to determine $E R C_{i}(x)$ and $R R C_{i}(x)$.

GO/NOGO decision making for a project on the basis of both internal and external risks should be validated through other criteria than the profit ratio. Furthermore, sensitivity analysis should be performed for the profit ratio with all input values.

A firm usually launches multiple numbers of NPD projects and allocates its most competitive resources to the projects. Therefore, it should establish a logical project management system to evaluate the project performance shown under various risk scenarios. This study developed a framework to predict the project performance in terms of profit. The framework can predict the profit to be made by a project at any gate of the entire NPD process. If a project is expected to have low profitability through the model due to various reasons at a given time point, it would change its goal and objective or be terminated.

A quantitative model is developed to predict the profit ratio at any gate of the entire NPD process. The model reflects all costs related to both NPD project and risks. A project manager can evaluate the project performance in terms of profit predicted at a gate. The firm should have a large scale database from previous NPD projects in which essential data sets such as project types, project costs are invested in stages, stage lengths, risk types and response strategies, risk occurrences, estimated risk impacts, and critical parameter values to estimate the profit that can be extracted. Then, those parameter values are plugged into the developed model to obtain the optimal PR value and to make more scientific decision on the project lives. However, there are many issues to be solved in future including accuracy of data sets and missing values treatment methods.

\section{References}

Bae, Y. M., \& Lee, Y. H. (2011). Integrated risk management process to address the problem of assigning pilot missions to Korean army helicopter units. International Journal of Industrial Engineering: Theory, Applications and Practice, 18, 151-161.

Barton, R., \& Bobst, R. (1988). How to manage the risks of technology. Journal of Business Strategy, 9, 4-7.

Choi, H. G., \& Ahn, J. O. (2010). Risk analysis models and risk degree determination in new product development: A case study. Journal of Engineering and Technology Management, 27, 110-124.

Choi, H. G., \& Choi, D. (2012). Framework development for optimizing responses to NPD risks. International Journal of Management Science and Engineering Management, 7, 229-240.

Cooper, R. G. (1999). The invisible success factors in product innovation. Journal of Product Innovation Management, 16, 115-133. 
Cooper, R. G. (2004). Benchmarking best NPD practices-1. Research Technology Management, 47, 31-43.

Cooper, R. G. (2008). Perspective: The stage-gate idea-to-launch process-update, what's new and NexGen systems. Journal of Product Innovation Management, 25, 213-232.

Deng, J. (1985). Grey system fundamental method. Wuhan, China: Huazhong Polytechnic University Press.

Dragan, L. M., Dragan, D. M., \& Mirjana, Z. M. (2010). Application of ranking method in evaluation of engineering investment projects. International Journal of Industrial Engineering: Theory, Applications and Practice, 17, 330-338.

Ernst, H. (2002). Success factors of new product development: A review of the empirical literature. International Journal of Management Review, 4, 1-40.

Griffin, A., \& Page, A. L. (1993). An interim report on measuring product development success and failure. Journal of Product Innovation Management, 10, 291-308.

Hillson, D. (1999). Developing effective risk responses. The 30th Annual Project Management Institute 1999 Seminars \& Symposium, Pennsylvania, USA.

Hillson, D. (2001). Extending the risk process to manage opportunities. International Journal of Project Management, 20, 235-240.

Kim, C. S., Kim, J. S., Lee, S. W., \& Choi, H. G. (2013). Evaluating effects of external factors on success of NPD projects. Journal of Advanced Management Science, 1, 118-123.

Kim, J., \& Wilemon, D. (2003). Sources and assessment of complexity in NPD projects. R\&D Management, 33, 15-30.

Li, B., Akintoye, A., Edwards, P., \& Hardcastle, C. (2004). Risk treatment preferences for PPP/PFI construction projects in the UK. The 20th Annual ARCOM Conference, pp. 1259-1268, Heriot Watt University.

Murmann, P. A. (1994). Expected development time reductions in the German mechanical engineering industry. Journal of Innovation Management, 11, 236-252.

Park, S. M., Kim, J. S., Lee, S. W., \& Choi, H. G. (2011). Degree of uncontrollable external factors impacting to NPD. International Conference on Design and Product Development, pp. 136-141, Montreux, Switzerland.

Polk, R., Plank, R. E., \& Reid, D. A. (1996). Technical risk and new product success: An empirical test in high technology business markets. Industrial Marketing Management, 25, 531-543.

Priest, J. W., \& Sanchez, J. M. (2001). Product development and design for manufacturing-A collaborative approach to producibility and reliability. Basel, Switzerland: Marcel Dekker.

Rubenstein, A. H., Chakrabarti, A. K., O'Keefe, R. D., Souder, W. E., \& Young, H. C. (1976). Factor influencing innovation success at the project level. Research Policy, 10, 15-20.

Song, W., Ming, X., \& Xu, Z. (2013). Risk evaluation of customer integration in new product development under uncertainty. Computers \& Industrial Engineering, 65, 402-412.

Song, X. M., \& Montoya-Weiss, M. M. (1998). Critical development activities for really new versus incremental products. Journal of Product Innovation Management, 15, 124-135.

Walid, B., \& Oya, I. T. (1996). A new framework for determining critical success/failure in project. International Journal of Project Management, 14, 141-151.

Wang, Y. M., Liu, J., \& Taha, M. E. (2008). An integrated AHP-DEA methodology for bridge risk assessment. Computers \& Industrial Engineering, 54, 513-525. 